Santa Clara University

Scholar Commons

Communication

College of Arts \& Sciences

$6-27-2016$

\title{
How do presence, flow, and character identification affect players' empathy and interest in learning from a serious computer game?
}

Christine Bachen

Santa Clara University, cbachen@scu.edu

Pedro F. Hernández-Ramos

SantaClara University, phernandezramos@scu.edu

Chad Raphael

Santa Clara University, craphael@scu.edu

Amanda Waldron

Follow this and additional works at: https://scholarcommons.scu.edu/comm

Part of the Communication Commons, and the Education Commons

\section{Recommended Citation}

Bachen, C. M., Hernández-Ramos, P. F., Raphael, C., \& Waldron, A. (2016). How do presence, flow, and character identification affect players' empathy and interest in learning from a serious computer game? Computers in Human Behavior, 64, 77-87.

http://dx.doi.org/10.1016/j.chb.2016.06.043

(C) 2016. This manuscript version is made available under the CC-BY-NC-ND 4.0 license

This Article is brought to you for free and open access by the College of Arts \& Sciences at Scholar Commons. It has been accepted for inclusion in

Communication by an authorized administrator of Scholar Commons. For more information, please contact rscroggin@scu.edu. 
Bachen, C. M., Hernández-Ramos, P. F., Raphael, C., \& Waldron, A. (2016). How do presence, flow, and character identification affect players' empathy and interest in learning from a serious computer game? Computers in Human Behavior, 64, 77-87.

\title{
Pre-publication version
}

\begin{abstract}
This study develops and tests an integrated model of how three psychological variables - presence, flow, and character identification-contribute to interest in learning and empathy with people from other cultures through a simulation game. U.S. college students played one of two roles (an American journalist or Haitian survivor) in the game that dealt with the aftermath of the 2010 Haiti earthquake. Presence was a powerful predictor of flow, character identification, and empathy felt during the games. Furthermore, empathy experienced by game play significantly predicted interest in learning more about the game topics. Flow and identification made secondary contributions to learning outcomes, with flow mediating the effect of presence on males' empathy and identification contributing to females' interest in learning. While the proposed model was generally successful at predicting outcomes, it did a better job of accounting for the experience of participants who played a role rooted in their own culture (the journalist) than in a different culture (the survivor), and for female than male players. Our results suggest that serious game designers should prioritize inducing empathy and immersive presence in players, giving secondary attention to designing for flow and character identification.
\end{abstract}




\section{Introduction}

Within the rich spectrum of electronic and online games and simulations, "serious games" are designed primarily for learning rather than for entertainment. Game-based learning can be described as "an environment where game content and game play enhance knowledge and skills acquisition, and where game activities involve problem solving spaces and challenges that provide players/learners with a sense of achievement” (Qian \& Clark, 2016, p. 51). Serious games can be effective in promoting prosocial development and learning addressing a wide range of topics, including health, the environment, human rights, and international relations, in part through their ability to engage interest, motivate effort, encourage task persistence (Kirkley, Duffy, Kirkley \& Kremer, 2011; Mayer, 2014; Wouters, van Nimwegen, van Oosterdorp, \& van der Spek, 2013), and to present situated, problem-based learning opportunities (Connolly, Boyle, MacArthur, Hainey, \& Boyle, 2012).

This study examines learning within a serious game dealing with the 2010 earthquake in Haiti that contains scenarios about the damage from the earthquake, the international aid response, and the challenges facing Haitians, journalists, and aid workers after the earthquake. Besides gaining information about the earthquake, the game may promote empathy - a disposition that some educators (Colby, Ehrlich, Beaumont, \& Stephens, 2003; Nussbaum, 1997) and game designers (Flanagan \& Nissenbaum, 2014) argue is especially important for students to learn as part of civic and moral education.

To better understand the impact of serious games and more effectively design games for cognitive and affective learning, we need to know more about the ways in which players engage with the game during game play. Research demonstrates that several forms of player engagement in a game can enhance game-based learning, including immersion in the environment and 
interactions of the game world known as presence (Konijn \& Bijvank, 2009; Moreno \& Mayer, 2002), pleasurable absorption in game play through the flow state (Fu, Su, \& Yu, 2009; Weibel \& Wissmath, 2011), and identification with one's character in the game (Bachen, HernándezRamos, \& Raphael, 2012; Cohen, 2006; Lin, 2013).

Previous studies have focused on the relationship between one or two of these forms of player engagement and outcomes from game play. This study addresses the relationship among all three — presence, flow, and identification — within a single model grounded in theory and empirical research. The learning outcomes studied are aligned with several desired outcomes of digital game-based learning (DGBL) identified by All, Castellar, and Van Looy (2015), including attainment of the learning goals as defined beforehand by the game developer ${ }^{1}$, increased interest in the subject matter treated in the game, and transfer (the portability of the learned subject matter in the game to real world settings). We focus on the game's ability to foster empathy and interest in learning more about natural disasters and international responses to them. Additionally, we investigate how the relationships among variables in the model are affected by gender of the player and the character role played within the game to better understand how other player and/or game characteristics shape engagement in and outcomes from game play. We test this model using data from a study of U.S. students' reactions to Inside the Haiti Earthquake (PTV Productions, 2010).

2. Key concepts and their relationships

2.1 Presence, flow, and identification and learning from games

${ }^{1}$ Players are introduced to the game's purpose on Inside Haiti Earthquake website and are informed that the simulation will be "challenging assumptions about relief work in disaster situations" and asking players to take the role of aid worker, journalist and/or survivor in order "to commit to various strategies, and experience their consequences" (http://www.insidedisaster.com/experience/). 
In their meta-analysis of games and learning, Connelly et al. (2012) called upon researchers to examine the motivational features of game-based learning and serious games in more detail, to better understand how and under what conditions games contribute to learning. We address this by focusing on three player experiences correlated with interest, motivation, and learning from games: presence, flow, and identification with game characters. These experiences are particularly relevant to learning outcomes expected from the Inside the Haiti Earthquake game that uses actual video footage in character-driven scenarios related to the aftermath of the earthquake. The literature reviewed below focuses on research findings related to each of these variables and learning outcomes, and relationships among the three variables themselves within game studies.

Engagement or involvement is a critical component in theories explaining learning from games (Mayer, 2014; Yun Dai \& Wind, 2011). Engagement can occur through the experience of presence, defined as "the perceptual illusion of nonmediation" felt by media users when they project themselves into the physical or social space of the medium (Lombard \& Ditton, 1997, I[30). Prior research suggests that presence and realism are especially critical mechanisms of game-based learning because they improve players' concentration, allow players to learn actively rather than passively, and afford personalized learning based on players' choices and discovery of their consequences (Konijn \& Bijvank, 2009). A number of different types of presence have been identified (e.g., spatial, physical, social, self), but in this study we focus on one dimension: immersive presence, which refers to feelings of involvement and absorption, perceptually and psychologically, in the mediated environment (Lombard \& Ditton, 1997). Previous studies find that immersive presence influences motivation to continue playing and interest in relevant learning outcomes of games (Moreno \& Mayer, 2002), and that this kind of presence can boost 
learning outcomes if players are not cognitively overloaded by the game environment (Schrader \& Bastiaens, 2012).

A second mechanism that produces positive outcomes for learning is when players experience flow, a state of profound enjoyment and concentration experienced during activities in which a person's skills match the challenge of the task (Csikszentmihalyi, 1990). Flow is a significant predictor of game experiences and outcomes (Nah, Eschenbrenner, Zeng, Telaprolu, $\&$ Sepehr, 2014).

According to flow theory, we experience flow when an activity's challenges fully engage our skills, without overwhelming them. Games that promote flow have been theorized to increase players' motivation to play and therefore to boost their learning (e.g., Garris, Ahlers, \& Driskell, 2002).

Csikszentmihalyi initially identified eight possible dimensions of flow:

(a) a clear sense of what has to be done moment by moment; (b) immediate feedback as to how well one is doing; (c) an intense concentration of attention; (d) a balance between opportunities for action (challenges) and capacity to act (skills); e) exclusion of irrelevant content from consciousness; (f) a sense of control over the activity; (g) a distortion of sense of time - usually hours pass by in minutes; and (h) a feeling that the activity is intrinsically rewarding, or worth doing for its own sake (2000: 381).

Subsequently, Csikszentmihalyi, Abuhamdeh, and Nakamura (2005) suggested that clear goals, feedback, and balance between challenges and skills are best understood as preconditions for achieving flow, while the other elements comprise the experience of flow itself.

There is empirical support that flow increases educational motivation and enjoyment (e.g., Fu, et al., 2009), and interest in learning and empathy (e.g., Raphael, Bachen, \& 
Hernández-Ramos, 2012). Research studies are more mixed in their findings about flow's impact on other, more direct, learning outcomes. Some of the more rigorous empirical studies, using objective measures of learning rather than self-reports, do find that flow enhances task performance within a game (Engeser \& Rheinberg, 2008; Keller \& Bless, 2008; Lee \& Chen, 2009; Liu, Cheng, \& Huang, 2011). A recent study that used an observational method of both engagement (flow) and performance also found them to be positively related in children in a variety of different types of games (Martinovic, Burgess, Pomerleau, \& Marin, 2016).

Other studies, however, find that flow is not uniformly predictive of all forms of learning. For example, Admiraal, Huizenga, Akkerman, and Dam (2011) found flow was associated with team performance in a medieval history game, but not with student performance on a conceptual test. The authors posit that may have been due to the fact that game play was too limited, taking place over just one day. Another explanation offered in a meta-analysis on the effectiveness of serious games is that while players are more motivated, satisfied, and engaged than those in a traditional learning group, they may be distracted from the content of the actual learning activity (Girard, Ecalle, \& Magnant, 2013).

A third mechanism for facilitating engagement and subsequent learning through games is through player identification with a character, avatar, or role. Identification can be defined as "an imaginative process through which an audience member assumes the identity, goals, and perspective of a character" (Cohen, 2006, p. 261). Initially theorized for other forms of media, Cohen (2006) proposed that identification with media characters leads to a number of educational outcomes, including greater attention to and retention of messages associated with those characters. More than other media, games are particularly well-suited to promoting identification because they allow a player to direct the actions, choose the attributes, pursue the 
goals, and experience the feelings of a character who represents the player in the text (Happ, Melzer, \& Steffgen, 2013; Klimmt, Hefner, \& Vorderer, 2009). A study of students' identification with characters in violent video games found that identification with violent characters positively predicted aggressive affect and cognition, but identification did not mediate between level of interactivity of the medium (game versus movie) and aggression or arousal. Identification with the character played in a life simulation game predicted higher levels of global empathy in high school student players, along with greater interest in the subject matter of the game (Bachen et al., 2012). Identification with an avatar in a MMOG explained 50 percent of the variance using a more general measure of empathy (Van Looy, Courtois, De Vocht, \& De Marez, 2012).

\subsection{Relationships among presence, flow, and identification}

Some game research has included measures of both presence and flow (e.g., Jin, 2011, 2012; Weibel \& Wissmath, 2011). Weibel and Wissmath (2011), using factor analysis, found that presence and flow are distinct, but related, constructs that involve experiences of immersion. They define presence as "the sensation of being there in the mediated world," whereas flow refers to "the sensation of being involved in the gaming action" (p. 1).

Faiola, Newlon, Pfaff, and Smyslova (2013) established that presence and flow were significantly correlated for participants in Second Life. Weibel and Wissmath's (2011) research posited that presence was an antecedent to flow, and found that presence explained a significant amount of the variance in flow. In addition, flow was a significant influence on enjoyment as well as performance. In addition, two studies by Jin $(2011,2012)$ also established presence as an antecedent to flow, and tested the connection between flow and behavioral intentions. Jin (2011), in a series of studies with different simulation games, employed structural equation modeling to 
establish that several forms of presence-physical presence (perceiving virtual objects as real), spatial presence (being transported to a virtual location), and self-presence (identifying one's physical being with a virtual being) — predicted the experience of flow, findings that were then reconfirmed in a later study (Jin, 2012). Although the results in Jin (2011) showed that flow was a significant predictor of behavioral intentions, the analysis employed did not conclusively demonstrate the unique contributions of flow versus presence on that outcome variable.

Few studies have investigated the relationship between either presence or flow and identification. Jin (2011) found a relationship between two related measures - character identification, defined as “a temporal shift of players' self-perception through adoption of valued properties of the game character" (following Klimmt, et al., 2009, p. 351), and experiences of self-presence defined as "a psychological state in which virtual self/selves are experienced as the actual self in either sensory or nonsensory ways" (Lee, 2004, p. 46). While it may be expected that character identification is associated with self-presence given the close alignment of the two constructs, it can be hypothesized that other forms of presence (physical, spatial, immersive) or flow could also lead to the development of stronger character identification through the player's deepened engagement in a realistic virtual environment.

\subsection{Learning outcomes and control variables}

Building on the results of past research on the impact of presence, flow, and identification and the goals of the game, two types of learning are of particular interest: empathy and interest in learning more about the subject matter of the game.

Empathy can be defined as "an other-oriented emotional response elicited by and congruent with the perceived welfare of someone else" (Batson, Ahman, \& Lishner, 2009, p. 418). Compared to antisocial or "neutral" games, prosocial games have been found to increase 
empathy and decrease schadenfreude, or pleasure taken at another's misfortunes (Greitemeyer, Osswald, \& Brauer, 2010). Darfur Is Dying (Susana Ruiz, 2005) is an example of a serious game in which empathy is a value promoted throughout the narrative premise, characters, player choices, and context of play (Flanagan \& Nissenbaum, 2014). In a study of this game, players were more willing to help in the crisis than those who read a text conveying the same information and those who observed the game as a kind of animation (Peng, Lee, \& Heeter, 2010). Other research finds that global empathy, a construct that measures empathy with people from other cultures, can also be enhanced through game play: a life simulation game was more successful in promoting global empathy compared to a control group that used other instructional means to explore the issues experienced by individuals in the same country as the simulation (Bachen et al., 2012).

Interest in learning about the subject matter of a game is a well-supported outcome of educational game play in the scholarly literature on serious games (Young et al., 2012). Interest is also strongly predictive of other learning outcomes, such as focus, persistence, effort, and knowledge and skill acquisition (Hidi \& Ainley, 2008) and motivation (Krapp, Hidi, \&Menninger, 2014).

In our study, we test hypothesized relationships among presence, flow, and identification and our two outcome measures - empathy and interest in learning — within an integrated model. We then test the fit of our model factoring in the gender of our players and the role they played in the simulation game. Studies of games have found gender to be an important determinant of game play, including the variables of interest in this study. Some research has found that males and females experience presence differently (Ratan, 2011), but observe that the direction of the difference is not consistent across genres. Research has also identified gender differences in the 
experience of flow, with males achieving higher level of flow than females (Voiskounsky \& Wang, 2014).

In addition, females sometimes report that game-based learning is less interesting and enjoyable than males do (e.g., Bonanno \& Kommers, 2008), although we note that these differences may be explained by other factors, especially amount of prior experience with game play and whether games are perceived as easy to use (Bourgonjon, Valcke, Soetaert, \& Schellens, 2010). Gender differences have also been also associated with the dependent variable of empathy. While considerable research supports the finding that females are more empathetic than males (see Toussaint \& Webb, 2005), some scholars suggest that the differences are contextual, and by methodological suspicions that females' higher self-reports of empathy may stem from social desirability effects of internalized sex stereotypes (Eisenberg, Spinrad, \& Sadovsky, 2006).

Because participants played two different roles in the game used in this study, game role was also tested in the model. In this study, participants played either a western male journalist covering the aftermath of the earthquake or a female Haitian survivor. As Hefner, Klimmt, and Vorderer (2007) have noted when players assume a role in the game they are exerting agency in that role. Given the significant variation in these two game roles, it is important to examine whether the relationships among the key predictor and outcome variables in the model are consistent across the two roles.

\section{The model and hypotheses}

Figure 1 summarizes our model based on the theoretical and empirical relationships identified in past research. The specific hypotheses are depicted in the model, followed by a brief rationale. 


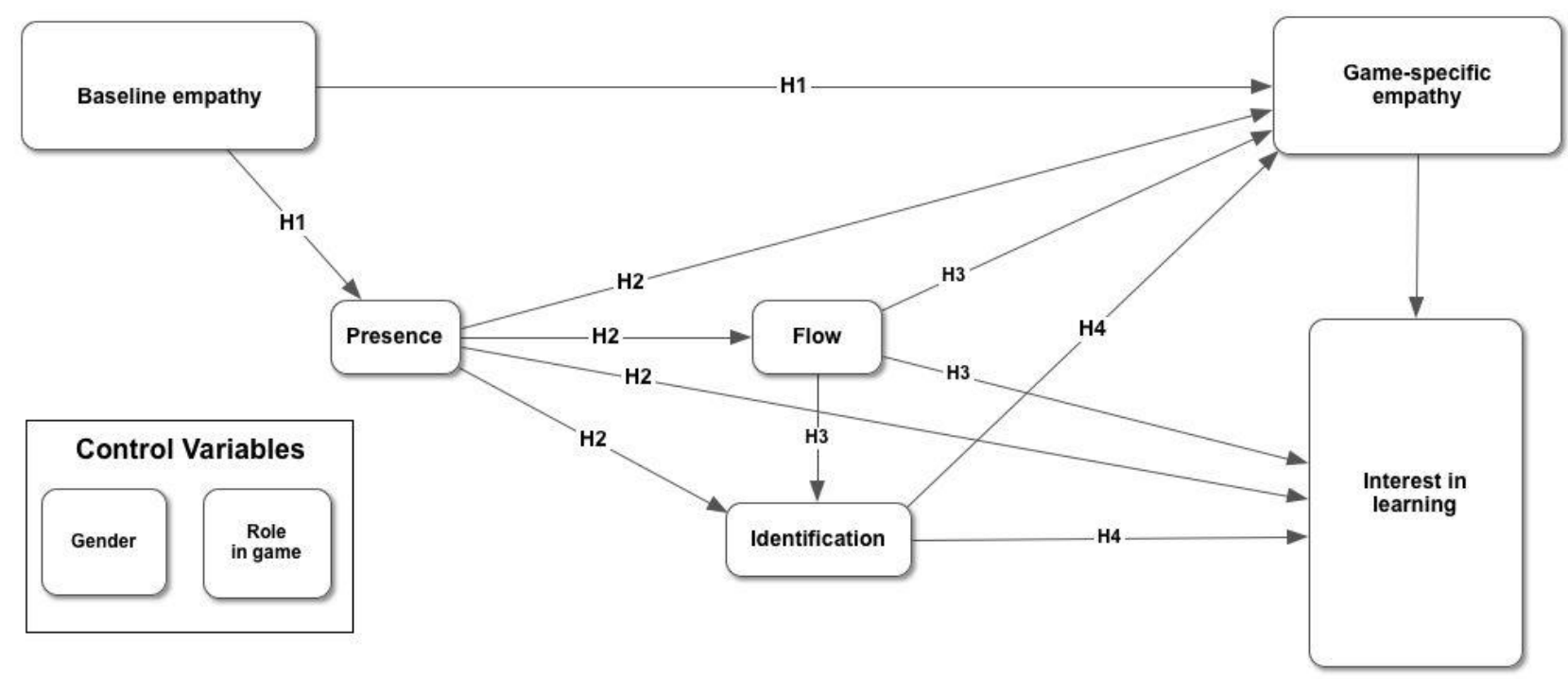

Figure 1. Diagram of the theoretical model

\subsection{Hypotheses}

While the research has produced some mixed findings about certain relationships (e.g., between flow and learning) or has varied in its explication and measurement of key constructs (e.g., presence and empathy), the hypothesized relationships within the model shown in Figure 1 have received some support or can be extrapolated from theory.

H1: Baseline global empathy (measured pre-game) will positively influence presence and game-specific empathy. Research has documented the importance of prior empathy's impact on presence (e.g., Nicovich, Boller, \& Cornwell, 2005). Accounting for its impact allows us to draw more specific conclusions about the impact of the game.

H2: Presence will positively contribute to flow, identification, game-specific empathy, and interest in learning. The more that participants feel immersed in the simulation experience, the greater the likelihood that they will enter a state of flow as they complete game tasks (e.g., Jin, 2011, 2012). As players feel more involved and absorbed, it follows that they will identify more with their character (e.g., Jin, 2011), express greater empathy for the people represented in the game after playing 
(Greitemeyer, et al., 2010), and be more interested in learning about the issues these people face (Weibel \& Wissmath, 2011).

H3: Flow will positively influence identification (Jin, 2011), game-specific empathy (Raphael et al., 2012), and interest in learning more about the subject matter of the game (Fu et al., 2009; Raphael et al., 2012).

H4: Identification will positively contribute to game-specific empathy and interest in learning more about the subject matter of the game (Bachen et al., 2012).

In addition to these hypothesized relationships among individual variables, we propose that taken together they will significantly contribute to a model explaining game-specific empathy and interest in learning. In that model we will be able to see more clearly the relationships among independent variables and identify the relative contributions of each in explaining game-specific empathy and interest in learning. Within that model, we also examine the effect of players' gender on the relationships in the model as well as the effect of the role played in the game.

\section{Method}

\subsection{Participants}

Data were collected at a private California university from 146 undergraduates (54 males, 92 females) ranging in age from 18 to 24 (Median = 20), with the exception of one older student. Participants were recruited voluntarily from 13 different sections of five different communication courses.

\subsection{Game}

Participants played Inside the Haiti Earthquake, a simulation available online for free (http://www.insidedisaster.com/experience/) (see Figure 2). 


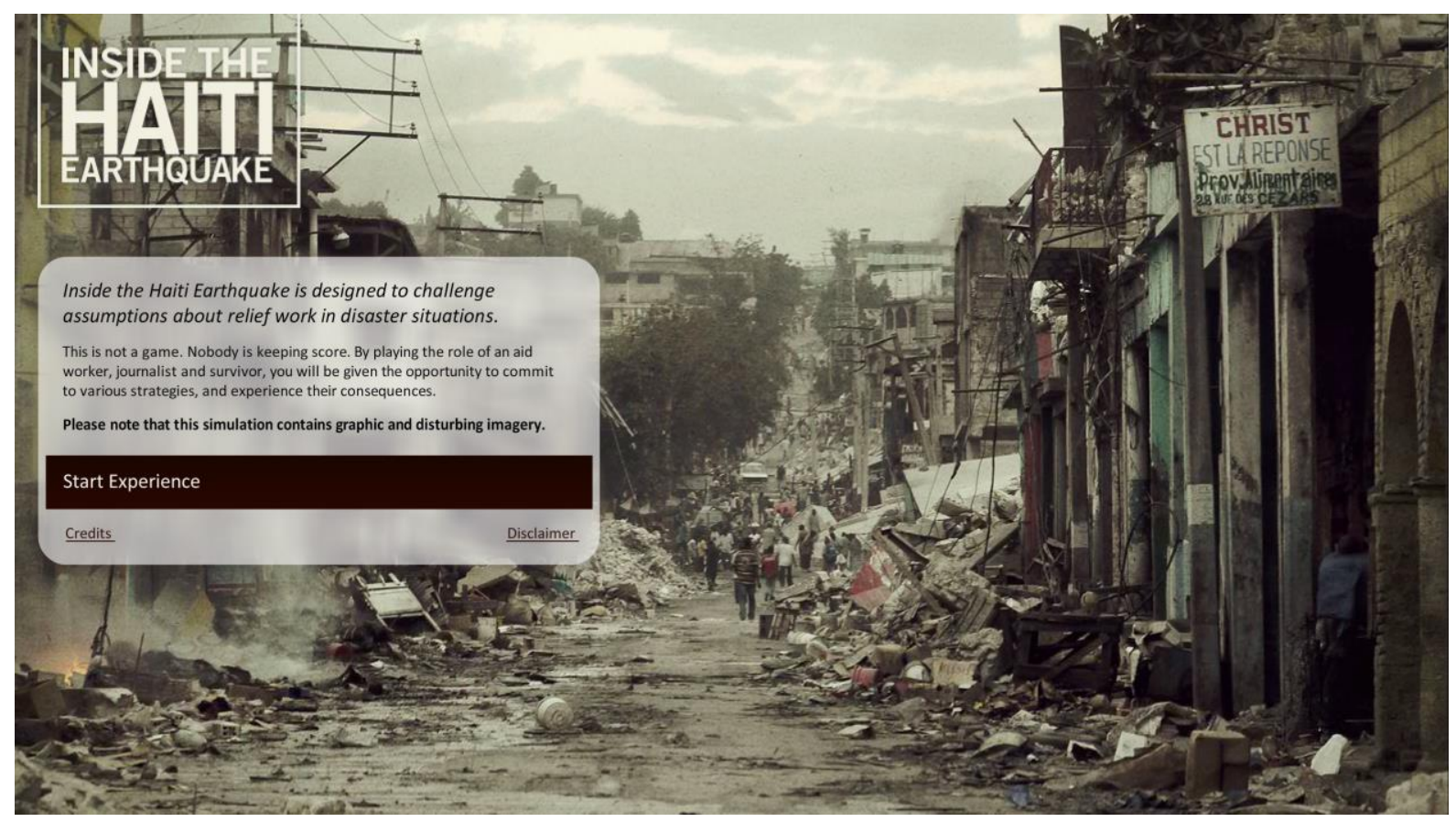

Figure 2. The opening screen of Inside the Haiti Earthquake.

Players performed the roles of an American journalist (a white, male professional from the developed world) or a survivor (Haitian, low-income, and female) of the real-world tragedy that struck the country in 2010 . Thus, these two roles offered opportunities to test whether players could identify with one character who was culturally distant from their experience (the survivor) and another that was more similar (the journalist, especially because the participants were enrolled in communication courses). In each role, players traverse a branching narrative in which they must decide how to cover the story accurately and from multiple perspectives (journalist) or find medical attention and food (survivor).

Haiti meets the conditions of a simulation game in that it models a set of conditions and rules (Warren, Jones, Dolliver, \& Stein, 2012), in this case for journalists and survivors of a natural disaster in the developing world. Like a game, it has specific win/loss conditions. For example, as the journalist, if you file stories that are framed inconsistently, you get fired. Haiti is also a documentary game (or docugame), which provides a historical record of an event and 
those who experienced it. Docugames aim to create a sense of social realism by representing real-world environments and narratives, and affording player actions that seem true to life (Bogost, Ferrari, \& Schweizer, 2010). Unlike many previous docugames, the Haiti interface represents events entirely through news photographs and especially through journalistic video footage, not computer graphics.

The game was chosen because of its potential to induce the psychological states relevant to the study. We anticipated that the realism of the game genre, subject, and interface would inspire a sense of presence. The video footage of recognizable, individual people, including many who are struggling to survive the aftermath of the quake or to help its victims, suggests the game may provoke empathy in the player for other characters. The challenges posed seem appropriate to college students, favoring flow. The game affords character identification and interest in learning because players are confronted with morally-charged dilemmas in each role, such as whether the journalist should report the sometimes chaotic and ineffective nature of the aid effort even if this might dampen donations, and whether the survivor should join others in "salvaging" food from a ruined grocery or shun "looting" from the store.

\subsection{Measures}

Presence was measured using all six items from the engagement (mental immersion) subscale from the Temple Presence Inventory (Cronbach's $\alpha=.919)$, developed by Lombard, Ditton, and Weinstein (2004). The 15-item scale measuring all eight dimensions of flow originated in $\mathrm{Fu}$, et al., (2009) and was adapted and validated in Bachen et al. (2012) and Raphael et al. (2012) (Cronbach's $\alpha=.815)$. Identification with the character played in the simulation was measured using a six-item scale developed and validated in Bachen et al. (2012) (Cronbach's $\alpha=.843$ ). Because the game used in this study challenged U.S. college students to 
empathize with people in a less developed country, the initial survey measured empathy using a 10-item version of the scale of global empathy adapted and validated in Bachen et al. (2012) and Raphael et al. (2012), based on Wang, et al. (2003) (Cronbach's $\alpha=.778$ ). This scale was modified for the post-game survey to measure players' game-specific empathy with Haitian people (Cronbach's $\alpha=.820$ ). On the post-game survey, a five-item scale measured interest in learning more about game topics, including "how aid organizations help survivors of natural disasters," "how disasters are reported in the media," "how disaster survivors cope," and "what's happening in Haiti after the earthquake" (Cronbach's $\alpha=.907)$.

\subsection{Procedure}

The study was introduced as a research project about games and learning. As incentives, students were offered a \$20 gift card and the satisfaction of assisting senior thesis students (with whom the data were gathered) with their research. Thus, there was a self-interested and an altruistic incentive. A pre-game survey to measure global empathy and demographic variables was administered via computer in a lab about a week prior to playing the game. Two guest professors, one male and one female, administered the initial survey and game play sessions to about half of the sample apiece. Game play occurred in students' regular classrooms during class time. Males and females in each course were randomly assigned to the journalist role $(N=71)$ or survivor role $(N=75)$. Participants were briefed on how to navigate the game, and then played it using headphones. All participants were able to reach the game's conclusion at least once; most students played more than once, exploring different choices in the same role. The post-game survey, which measured presence, flow, identification, game-specific empathy, and interest in learning was administered via computer in the classroom immediately after game play. 
To strengthen internal validity of the study, all game play occurred in the same classroom and all students played on computers with similar-sized screens, resolution, and mice. Students played for 20 to 25 minutes. The fact that students played in their own classroom as part of a regular course strengthened the external validity of the study's conclusions about effects on interest in learning.

\subsection{Statistical Analyses}

For statistical data analysis, we used the appropriate correlation, multiple regression, and structural equation modeling procedures in the Stata software package, version 13 (StataCorp, 2015). In order to be considered significant, individual paths between variables had to be $\mathrm{p}=$ $<.05$ and in the direction hypothesized in the model (See Figure 1). The cut-off points for the fit indices in the structural equation analysis were set as follows according to the guidelines suggested by Hu and Bentler (1999), Hooper, Coughlan, and Mullen (2008), and Kenny (2014): non-significant Chi-square at the .05 level, RMSEA $\leq .06, \mathrm{SRMR} \leq .05, \mathrm{CFI} \geq 0.95$, and AGFI $\geq$ 0.90 .

\section{Results}

Table 1 presents the means, standard deviations, and correlations among all key variables included in our analyses. These data show that the game successfully induced high levels of flow, presence, and identification (with means generally well above the midpoints on each scale for these variables), although there was a good deal of variation in the sample. The means also show that the sample had high initial levels of global empathy and expressed almost equally high levels of empathy for the Haitian people after playing the game, as well as moderately high interest in learning more about the game topics, despite substantial variation among players. 
Table 1. Means, standard deviations (S.D.), and correlations for key variables.

\begin{tabular}{|l|r|r|r|r|c|c|c|c|c|c|}
\hline Variable & Mean & S.D. & \multicolumn{1}{|c|}{ Range } & (1) & (2) & (3) & (4) & (5) & (6) & (7) \\
\hline (1) Gender [1=M 2=F] & 1.63 & .48 & - & - & & & & & & \\
\hline (2) Role [0=Survivor 1=Journalist] & .49 & .50 & - & .036 & - & & & & & \\
\hline (3) Flow & 66.40 & 10.83 & $15-90$ & .042 & .013 & - & & & & \\
\hline (4) Presence & 31.26 & 6.66 & $6-42$ & .105 & .038 & $.530^{* * *}$ & - & & & \\
\hline (5) Identification & 26.95 & 5.97 & $6-36$ & .051 & -.133 & $.428^{* * *}$ & $.692^{* * *}$ & - & & \\
\hline (6) Baseline empathy & 44.17 & 7.16 & $10-60$ & .011 & -.028 & $.245^{* *}$ & $.354^{* * *}$ & $.323^{* * *}$ & - & \\
\hline (7) Game-specific empathy & 44.32 & 8.05 & $10-60$ & -.012 & -.063 & $.440^{* * *}$ & $.653^{* * *}$ & $.496^{* * *}$ & $.548^{* * *}$ & - \\
\hline (8) Interest in learning & 18.14 & 5.12 & $5-30$ & .079 & .049 & .129 & $.298^{* * *}$ & $.298^{* * *}$ & $.210^{*}$ & $.348^{* * *}$ \\
\hline
\end{tabular}

Note: ${ }^{*}=\mathrm{p}<.05 ;{ }^{* *}=\mathrm{p}<.01 ; * * *=\mathrm{p}<.001$

\section{Table 1. Means, standard deviations (S.D.), and correlations for key variables}

First, we will provide results for each of our hypotheses, and then report the structural equation modeling (SEM) analyses that considered the model as a whole, including the control variables of gender and role in the simulation.

As hypothesized, pre-game levels of global empathy positively influenced presence and levels of game-specific empathy (H1). Participants' levels of game-specific empathy were positively correlated with presence $\left(\mathrm{r}=.354, p=.000 ; R^{2}\right.$ from linear regression $\left.=.1253\right)$ and with game-specific empathy (r=.548. $p=.000 ; R^{2}$ from linear regression $\left.=.3005\right)$.

Presence did positively contribute to flow, identification, game-specific empathy, and interest in learning, as expected (H2). There was a positive correlation between presence and flow $(\mathrm{r}=.530, p=.000)$; presence explained $28.09 \%$ of the variance in flow. Presence and identification were positively correlated $(\mathrm{r}=.692, p=.000)$, with presence explaining $47.84 \%$ of the variance in identification. The relationship of presence to game-specific empathy was also strong ( $\mathrm{r}=.653, p=.000,42.59 \%$ of variance explained), but much weaker (although still positive) to interest in learning ( $\mathrm{r}=.298, p=.000,8.9 \%$ of variance explained).

Our third hypothesis, that flow would positively influence identification, game-specific empathy, and interest in learning, received partial support. Flow was significantly correlated with identification ( $\mathrm{r}=.428, p=.000,18.27 \%$ of the variance explained) and game-specific empathy 
$(\mathrm{r}=.440, p=.000,19.38 \%$ of variance explained $)$ but not with interest in learning $(\mathrm{r}=.129$, n.s., $1.66 \%$ of variance explained).

Finally, we found support for H4 that identification would positively contribute to gamespecific empathy and interest in learning. Identification was significantly related to gamespecific empathy ( $\mathrm{r}=.496, p=.000,24.56 \%$ of variance explained) and to interest in learning ( $\mathrm{r}=.298, p=.000,8.9 \%$ of variance explained $).$

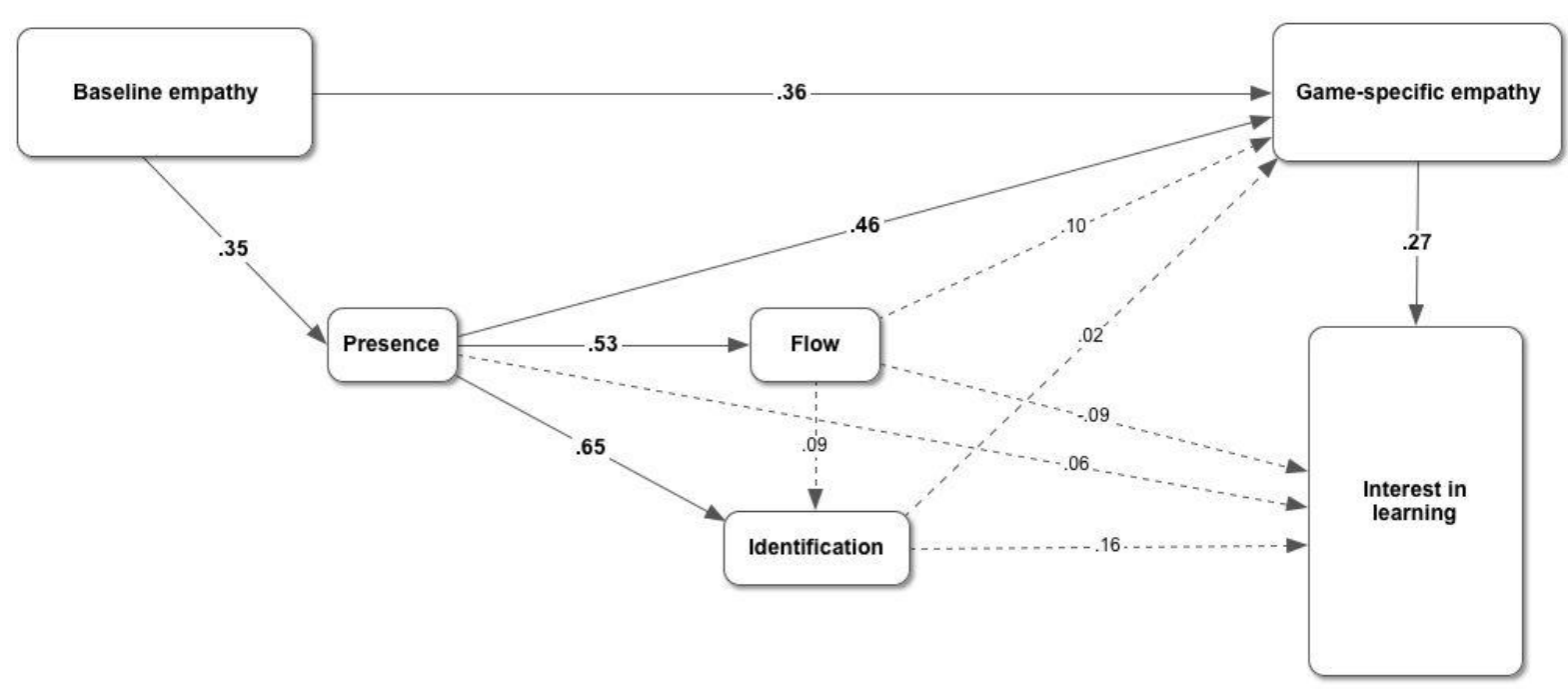

Figure 3. SEM results testing the model with the full sample $(\mathrm{N}=146)$

(Note: In this and other figures, solid lines indicate coefficient is significant at the .05 level or higher, while dashed lines indicate non-significance.)

We now turn to structural equation modeling to analyze the impact of all variables together in the model (see Figure 3). First, considering the entire sample $(n=146)$, the data were a good fit for the model $\left(X^{2}(3)=2.53, p=.469\right.$, RMSEA $=.000$, SRMR=.020), using goodness-offit criteria identified by $\mathrm{Hu}$ and Bentler (1999) and others as indicated above. Results showed that only game-specific empathy had a significant effect on interest in learning (Std. Coeff. $=.27$, $p=.007)$. Flow, identification, and presence had no significant direct effect on interest in learning, although the hypothesized positive influence of presence on both flow (Std. Coeff. $=.53, p=.000$ ) 
and identification (Std. Coeff. $=.65, p=.000$ ) was confirmed (see results for $\mathrm{H} 2$ and $\mathrm{H} 3$, above). Presence also had a significant effect on game-specific empathy (Std. Coeff. $=.46, p=.000$ ). Thus, for the sample as a whole, any influence of presence on interest in learning was mediated mainly by game-specific empathy. Post-hoc analysis of direct and indirect effects confirmed this: While the total effect of presence on interest in learning was .2459 , the direct effect was only $.0529(p=.651)$ but the indirect effect was $.193(p=.000)$.

While males and females, and players of the journalist and survivor roles, ended with indistinguishable levels of game-specific empathy and interest in learning (as shown by t-tests), we wanted to know whether they arrived at these similar levels through the same combination of psychological influences. These next analyses allow us to see whether our model accounts equally well for the experiences of players of each gender and role when all variables are looked at simultaneously.

Overall, the data were a good fit for the model (males $\mathrm{n}=54, X^{2}(3)=3.78, p=.286$, SRMR=.052; females $\left.\mathrm{n}=92, X^{2}(3)=1.732, p=.630, \mathrm{SRMR}=.018\right)$. Four major differences are worth noting when comparing these analyses (see Figures $4 \mathrm{a}$ and $4 \mathrm{~b}$ ). First, in both groups presence was a significant predictor of both flow and identification, but only for females did flow significantly predict identification (Std. Coeff.=.17, $p=.038$ ). Second, for females, game-specific empathy was significantly influenced by presence (Std. Coeff.=.63, $p=.000$ ), but not for males (Std. Coeff.=.16, n.s.). Third, for males, flow (Std. Coeff.=.35, $p=.003$ ) influenced game-specific empathy, but not for females (Std. Coeff.=-.01, n.s.). Fourth, none of the hypothesized influences on interest in learning were significant for males, whereas for females both game-specific empathy (Std. Coeff.=.36, $p=.000$ ) and identification (Std. Coeff.=.29, $p=.042$ ) were significant predictors. Post-hoc tests for group invariance of parameters confirmed that the influence of 
presence $\left(X^{2}(1)=6.621, p=.010\right)$ and flow $\left(X^{2}(1)=6.046, p=.014\right)$ on game-specific empathy operated in significantly different ways for males and females in this study.

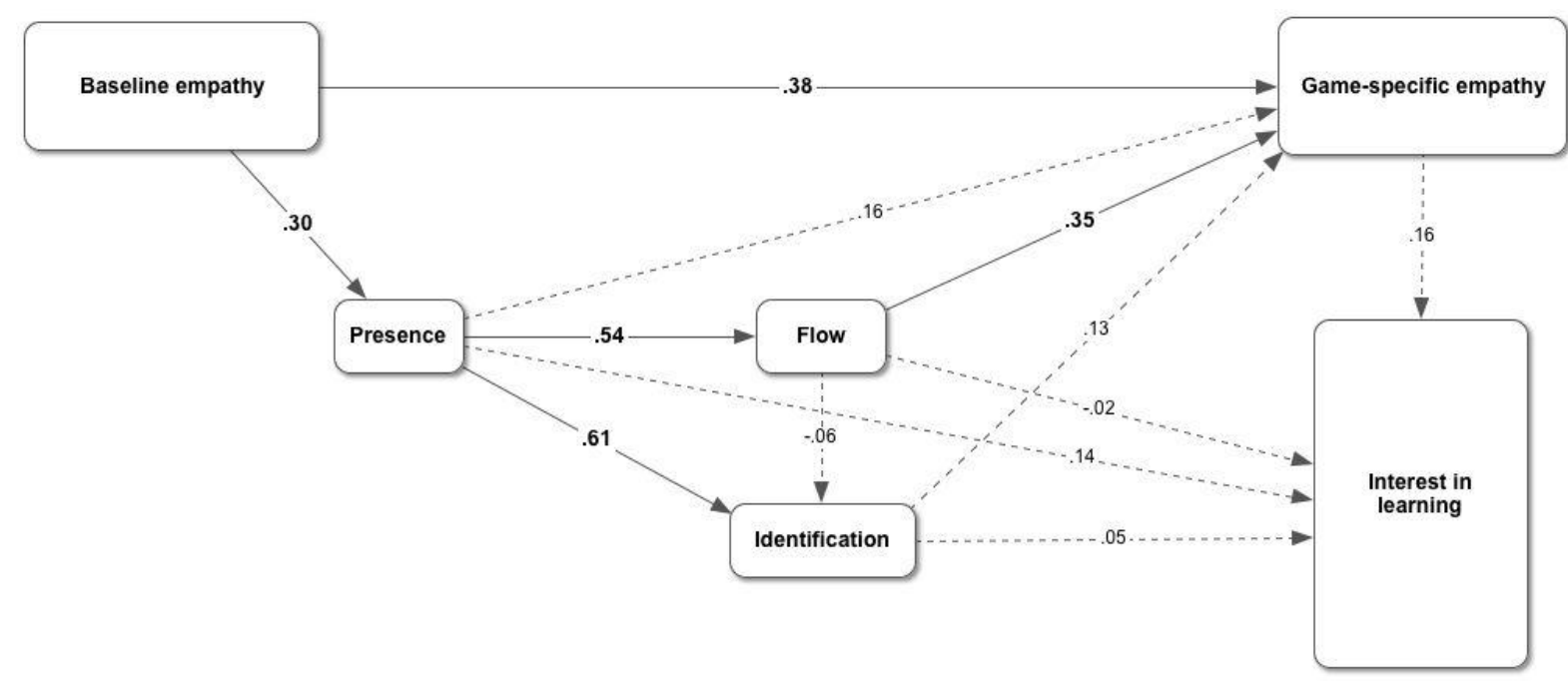

Figure 4a. SEM results for males $(n=54)$

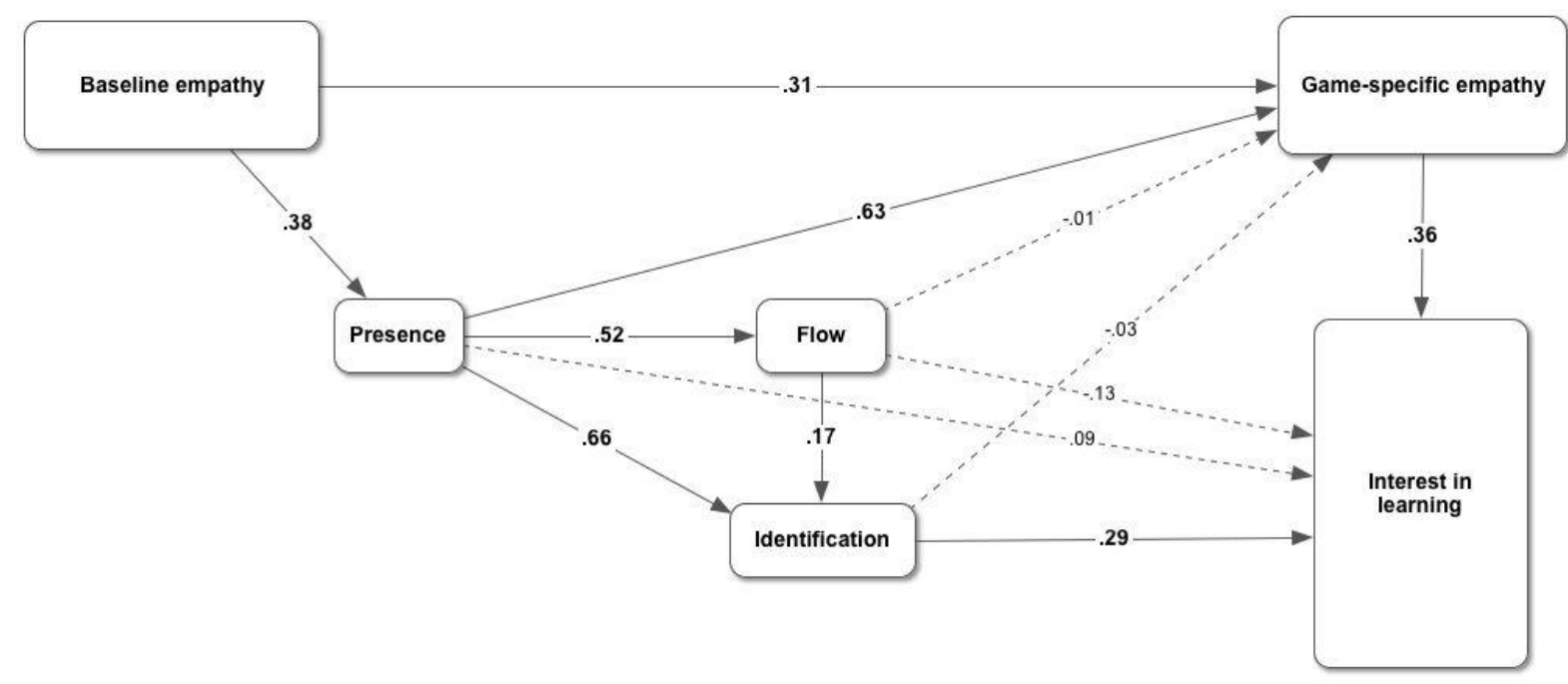

Figure $4 b$. SEM results for females $(n=92)$

In sum, these models showed notable gender differences. For males, experiencing flow in the game influenced game-specific empathy toward the people affected by the Haiti earthquake, but did not influence their interest to learn more about the situation. In contrast, females' 
empathy was not influenced by a sense of flow in the game, but identification affected their interest in learning more about the situation after the disaster along with empathy. It is worth remembering here that individual t-tests showed no significant differences by gender on any of the variables in the model tested in this study, so one benefit of SEM in this case is that it allows us to better understand the subtle differences in how males and females experienced the game.

As was the case with gender, overall the data were a good fit for the model for both roles (see Figure 5a for journalist, $X^{2}(3)=1.315, p=.725, \mathrm{SRMR}=.025$; see Figure $5 \mathrm{~b}$ for Haitian survivor, $\left.X^{2}(3)=4.991, p=.172, \mathrm{SRMR}=.037\right)$. However, among Haitian survivors, baseline global empathy (Std. Coeff.=.55, $p=.000)$ was a significant influence on presence, but not among those playing the journalist (Std. Coeff.=.08, n.s.). Additionally, among participants who played as a survivor none of the predictors of interest in learning (game-specific empathy, flow, identification, or presence) were significant, whereas for players in the journalist role both gamespecific empathy (Std. Coeff. $=.48, p=.000)$ and identification (Std. Coeff. $=.27, p=.029)$ were significant predictors. Post-hoc tests for group invariance of parameters confirmed that those who played as the journalist (Std. Coeff.=.077, n.s.) and those who played as the survivor (Std. Coeff. $=.55, p=.000)$ differed significantly on how baseline global empathy affected presence $\left(X^{2}\right.$ $(1)=16.344, p=.000)$. 




Figure 5a. SEM analysis for participants who played as journalist $(n=71)$

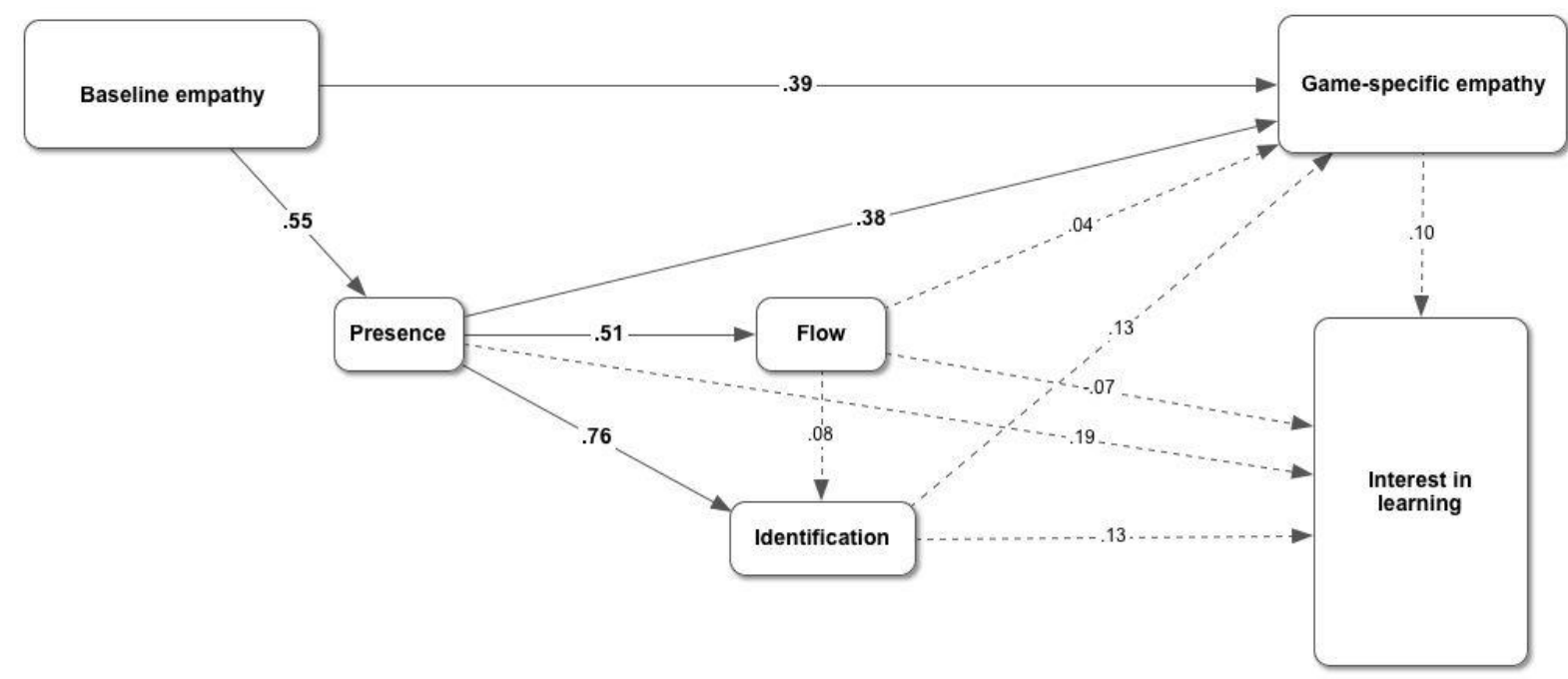

Figure 5b. SEM analysis for participants who played as Haitian survivor (n=75)

In summary, there were also notable differences in the results by role played in the game. While presence and baseline global empathy influenced game-specific empathy for both groups, their pathways to interest in learning differed. For those who played as the journalist, 
identification and game-specific empathy positively influenced interest in learning, whereas for those who played as the survivor none of the predictors were significant.

\section{Discussion}

This study set out to explore the inter-relationships among a set of factors that can influence empathy and interest in learning more about a topic of study. Our analyses of sets of pairs of relationships confirmed some patterns we had seen in previous research cited above. Presence, flow, and identification were significantly related and were linked to two outcomes: empathy for people represented in the game and interest in learning.

Structural equation modeling allowed for comparing the relative power of a unique set of variables, showing that some factors played a more important role in explaining game outcomes than others. When testing the model with the whole sample, we found that interest in learning was only directly influenced by game-specific empathy and not directly by any of the other game play variables (presence, flow, identification). This suggests that designers of serious games would be wise to prioritize creating interfaces and game play that encourage players to engage with the cognitive, emotional, and communicative experiences of peoples from other cultures. In this light, empathy for others is not just a worthy disposition for global citizens, but a powerful key for unlocking interest in other cultures.

Immersive presence emerged as an important state that is both influenced by a player's base level of global empathy and also enhances empathy for people from other cultures in a game. Both findings align with prior research (Greitemeyer et al., 2010; Nicovich et al., 2005).

The fact that immersive presence also had a strong positive influence on both flow and identification regardless of player gender or game role reinforces that presence is also a crucial dimension of serious game design. Deep immersion in the game world seems to have allowed 
players to experience Haitians' lives as real and achieve empathy with them. Presence may be especially helpful to female players, given our finding that this state had a direct positive effect on females' experience of game-specific empathy for Haitians. The use of video footage of actual historical events in this game may be particularly effective at inspiring perceptual and psychological immersion in the game environment.

The fact that flow and identification made secondary contributions to our outcome variables, both of which varied by players' gender, suggests that fostering these states may be valuable but insufficient goals for educational game design. For males, flow mediated the contribution of presence to game-specific empathy, while for females identification emerged as a positive influence on both flow and interest in learning. It may be that males are somewhat more likely than females to develop cognitive and emotional connections to people represented in games by engaging in tasks posed by game play. Females may be more likely than males to have their interest in other peoples piqued by inhabiting a game character from another culture, which jibes with many females' greater interest in role-playing fantasy games than in first-person shooter games that largely appeal to males (Bourgonjon et al., 2010). If so, the goal of designing gender-inclusive educational games and simulations might be served well by striving to induce both flow (especially to engage males empathetically with other cultures) and identification (to interest females in other peoples).

However, the students in our study related better to the virtual experience of the American journalist covering the disaster: the combined effects of identification with the journalist role and game-specific empathy for the Haitian people made a significant contribution to interest in learning more about the game topics, which was not the case for those who played as the survivor. We suspect that the cultural barriers to empathy identified by Rasoal, Eklund, 
and Hansen (2011) may also help to account for the diminished role of identification among players of the survivor role. Lack of knowledge and experience of a different culture, and inability to perceive similarities and differences between another culture and one's own, may be obstacles to identifying with a character from another country, ethnicity, or social class. One implication is that game designers and educators may need to acknowledge that developing identification with people who are perceived as psychologically or geographically distant requires more extended interventions in surrounding lesson plans and supplementary materials that prepare students to immerse themselves in a different culture.

\section{Conclusion}

This study offered an integrated model of how several forms of player engagement in serious game play contribute to interest in learning and empathy with people from other cultures. The experience of immersive presence emerged as a powerful predictor of flow, character identification, and game-specific empathy_even when controlling for pre-game levels of global empathy. When we turned to interest in learning more about Haiti and topics related to the earthquake, game-specific empathy emerged as the only significant predictor, with other factors mediated through this variable. Flow and identification made lesser contributions to learning outcomes that were dependent on players' gender, with flow mediating the effect of presence on males' game-specific empathy and identification contributing to females' interest in learning. While the proposed model was generally successful at predicting outcomes, it did a better job of accounting for the experience of participants who played a role rooted in their own culture and professional aspirations (the journalist) than in a different culture and class (the Haitian survivor), and for female players compared to males. These results suggest that serious game designers should prioritize inducing empathy and immersive presence in players, giving 
secondary attention to designing for flow and character identification, and that educators should supplement games that challenge students to play characters from distant cultures and social backgrounds with additional lesson planning and instructional materials.

Future research can overcome some of the limitations of this study as well as strengthen and extend these findings in several ways. First, the differential power of the model at explaining outcomes for those who played a character more similar to themselves and those who played a role different from themselves indicates a need to test this model using larger and more culturally diverse samples. Second, the kinds of tasks assigned to players in games may affect empathy and interest in learning; future research should test whether socially-oriented tasks that are relevant to players and pose an appropriate level of challenge are most likely to spark interest in ongoing learning. Additionally, the fact that this study was limited to testing a single game means that the model should be tested on a broader range of serious games of different genres and subject matters. Whether the interface of the Haiti game accounted for the power of presence in this study should be examined by comparing games that rely mainly on computer graphics with those that use video footage, as well as by comparing fictional games with games that represent actual historical events. Finally, future research can examine whether enhanced interest in learning more about the game topics and game-specific empathy lead to acquisition of greater knowledge, skills, or dispositions that serious games aim to teach. For example, research conducted over more than thirty years shows that empathetic concern leads to altruistic motivation, or motivation with the ultimate goal of increasing another's welfare (Batson et al., 2009). While we did not include measures of altruism, behavioral intentions, or subject-matter learning in this study, we might surmise that global empathy would also predict a commitment to these kinds of socially valuable actions. 


\section{References}

Admiraal, W., Huizenga, J., Akkerman, S., and Dam, G. T. (2011). The concept of flow in collaborative game-based learning. Computers in Human Behavior, 27(3), 1185-1194

All, A., Castellar, E. P. N. \& Van Looy, J. (2015). Toward a conceptual framework for assessing the effectiveness of digital game-based learning. Computers \& Education, 88, 29-37.

Bachen, C. M., Hernández-Ramos, P. F., \& Raphael, C. (2012). Simulating REAL LIVES: Promoting global empathy and interest in learning through simulation games. Simulation \& Gaming, 43(4), 437-460.

Batson, C. D., Ahmad, N., \& Lisher, D. A. (2009). Empathy and altruism. In C. R. Snyder, Shane J. Lopez (Ed.) Oxford Handbook of Positive Psychology (pp. 417-426). New York: Oxford University Press.

Bogost, I., Ferrari, S., \& Schweizer, B. (2010). Newsgames: Journalism at play. Cambridge, MA: MIT Press.

Bonanno, P., \& Kommers, P. A. M. (2008). Exploring the influence of gender and gaming competence on attitudes towards using instructional games. British Journal of Educational Technology, 39(1), 97-109.

Bourgonjon, J., Valcke, M., Soetaert, R., \& Schellens, T. (2010). Students' perceptions about the use of video games in the classroom. Computers and Education, 54(4), 1145-1156.

Cohen, J. (2001). Defining identification: A theoretical look at the identification of audiences with media characters. Mass Communication \& Society, 4(3), 245-264.

Cohen, J. (2006). Audience identification with media characters. In J. Bryant and P. Vorderer (Eds.), Psychology of entertainment (pp. 183-197). Mahwah, NJ: Lawrence Erlbaum 
Associates.

Colby, A., Beaumont, E., Ehrlich, T., \& Corngold, J. (2007). Educating for democracy: Preparing undergraduates for responsible political engagement. San Francisco: JosseyBass.

Connolly, T. M., Boyle, E. A., MacArthur, E., Hainey, T., \& Boyle, J. M. (2012). A systematic literature review of empirical evidence on computer games and serious games. Computers \& Education, 59(2), 661-686.

Csikszentmihalyi M. (1990). Flow: The psychology of optimal experience. New York: Harper \& Row.

Csikszentmihalyi, M. (2000). Flow. In A. Kazdin (Ed.), The encyclopedia of psychology, vol. 3 (pp. 381-382). Washington, DC: American Psychological Association and Oxford University Press.

Csikszentmihalyi, M., Abuhamdeh, S., \& Nakamura, J. (2005). Flow. In A. J. Elliot \& C. S. Dweck (Eds.), Handbook of competence and motivation (pp. 598-608). New York: Guilford Press.

Eisenberg, N., Spinrad, T., \& Sadovsky, A. (2006). Empathy-related responding in children. In M. Killen \& J. Smetana (eds.), Handbook of moral development, vol. 1 (pp. 517-551). Mahwah, NJ \& London: Lawrence Erlbaum Associates.

Faiola, A., Newlon, C., Pfaff, M., \& Smyslova, O. (2013). Correlating the effects of flow and telepresence in virtual worlds: Enhancing our understanding of user behavior in gamebased learning. Computers in Human Behavior, 29(3), 1113-1121. 
Flanagan, M., \& Nissenbaum, H. (2014). Values at play in digital games. Cambridge, MA: MIT Press.

Fu, F. L., Su, R. S., \& Yu, S. C. (2009). EGameFlow: A scale to measure learners' enjoyment of e-learning games. Computers \& Education, 52(1), 101-112.

Garris, R., Ahlers, R., \& Driskell, J. E. (2002). Games, motivation, and learning: A research and practice model, Simulation \& Gaming, 33(4), 441-467.

Girard, C., Ecalle, J., \& Magnant, A. (2013). Serious games as new educational tools: how effective are they? A meta-analysis of recent studies. Journal of Computer Assisted Learning, 29(3), 207-219.

Greitemeyer, T., Osswald, S., \& Brauer, M. (2010). Playing prosocial video games increases empathy and decreases schadenfreude. Emotion, 10(6), 796-802.

Happ, C., Melzer, A., \& Steffgen, G. (2013). Superman vs. BAD man? The effects of empathy and game character in violent video games. Cyberpsychology, Behavior, and Social Networking, 16(10), 774-778.

Hefner, D., Klimmt, C., \& Peter Vorderer, P. (2007). Identification with the player character as determinant of video game enjoyment. In Proceedings of the 6th international conference on Entertainment Computing (ICEC'07), Lizhuang Ma, Matthias Rauterberg, and Ryohei Nakatsu (Eds.). Springer-Verlag, Berlin, Heidelberg, 39-48.

Hidi, S., \& Ainley, M. (2008). Interest and self-regulation: Relationships between two variables that influence learning. In D. H. Schunk \& B. J. Zimmerman (Eds.), Motivation and selfregulated learning: Theory, research, and applications (pp. 77-109). New York: Lawrence Erlbaum. 
Hooper, D., Coughlan, J., Mullen, M. (2008). Structural Equation Modelling: Guidelines for Determining Model Fit. Electronic Journal of Business Research Methods, 6(1), 53-60.

Hu, L., \& Bentler, P. M. (1999). Cutoff criteria for fit indexes in covariance structure analysis: Conventional criteria versus new alternatives. Structural Equation Modeling: A multidisciplinary Journal, 6(1), 1-55.

Jin, S-A. A. (2011). "I feel present. Therefore, I experience flow:” A structural equation modeling approach to flow and presence in video games. Journal of Broadcasting \& Electronic Media, 55(1), 114-136.

Jin, S-A. A. (2012) Toward integrative models of flow: effects of performance, skill, challenge, playfulness, and presence on flow in video games. Journal of Broadcasting \& Electronic Media, 56(2),169-186.

Keller, J. \& Bless, H. (2008). Flow and regulatory compatibility: An experimental approach to the flow model of intrinsic motivation. Personality and Social Psychology Bulletin, 34(2), 196-209.

Kenny, D. A. (2014). Measuring model fit. [website]. Retrieved July 15, 2015 from http://davidakenny.net/cm/fit.htm.

Kirkley J. R., Duffy, T. M., Kirkley, S. E., \& Kremer, D. L. H. (2011). Implications of constructivism for the design and use of serious games (pp. 371-394). In S. Tobias \& J. D. Fletcher (Eds.), Computer Games and Instruction. Charlotte, N.C.: Information Age Publishing Co. 
Klimmt, C., Hefner, D., \& Voderer, P. (2009). The video game experience as "true" identification: A theory of enjoyable alterations of players' self-perception. Communication Theory, 19(4), 351-373.

Konijn, A., \& Bijvank, M. N. (2009). Doors to another me. Identity construction through digital game play. In U. Ritterfeld, M. Cody, \& P. Vorderer, P. (Eds.), Serious games: Mechanisms and effects (pp. 179-203). New York \& London: Routledge.

Krapp, A., Hidi, S., \& Menninger, K. A. (2014). Interest, learning and development (pp. 3-25). In K. A. Renninger, S. Hidi, and A. Krapp (Eds.) The role of interest in learning and development, New York: Psychology Press.

Lee, K. M. (2004). Presence, explicated. Communication Theory, 14, 27-50.

Lee, C. Y., \& Chen, M. P. (2009). A computer game as a context for non-routine mathematical problem solving: the effects of type of question prompt and level of prior knowledge. Computers \& Education, 52(3), 530-542.

Lin, J. (2013). Identification matters: A moderated mediation model of media interactivity, character identification, and video game violence on aggression. Journal of Communication, 63(4), 682-702.

Liu, C. C., Cheng, Y. B., \& Huang, C. W. (2011). The effect of simulation games on the learning of computational problem solving. Computers \& Education, 57(3), 1907-1918.

Lombard, M., \& Ditton, T. (1997). At the heart of it all: The concept of presence. Journal of Computer Mediated Communication, 3(2). <http://onlinelibrary.wiley.com/doi/10.1111/j.1083-6101.1997.tb00072.x/full> (Retrieved 08.14). 
Lombard, M., Ditton, T. \& Weinstein, L. (2004). Measuring presence: The Temple Presence Inventory (TPI). < http://matthewlombard.com/research/p2_ab.html> (Retrieved 08.14).

Martinovic, D., Burgess, G. H., Pomerleau, C. M., \& Marin, C. (2016). Computer games that exercise cognitive skills: What makes them engaging for children? Computers in Human Behavior, 60, 451-62.

Mayer, R. E. (2014). Computer games for learning. An evidence-based approach. Cambridge, MA: The MIT Press.

Moreno, R., \& Mayer, R. E. (2002). Learning science in virtual reality multimedia environments: Role of media and methods. Journal of Educational Psychology, 94(3), 598-610.

Nah, F. F. H., Eschenbrenner, B., Zeng, Q., Telaprolu, V. R., \& Sepehr, S. (2014). Flow in gaming: literature synthesis and framework development. International Journal of Information Systems and Management, 1(1), 83-124.

Nicovich, S. G., Boller, G. W., \& Cornwell, T. B. (2005). Experienced presence within computer-mediated communications: Initial explorations on the effects of gender with respect to empathy and immersion. Journal of Computer-Mediated Communication, 10(2). DOI: 10.1111/j.1083-6101.2005.tb00243.x.

Nussbaum, M.C. (1997). Cultivating humanity: A classical defense of reform in liberal education. Cambridge, MA: Harvard University Press.

PTV Productions (2010). Inside the Haiti Earthquake. $<$ http://www.insidedisaster.com/experience/> (Retrieved 08.14).

Peng, W., Lee, M., \& Heeter, C. (2010). The effects of a serious game on role-taking and willingness to help. Journal of Communication, 60(4), 723-742. 
Qian, M., \& Clark, K. R. (2016). Game-based learning and $21^{\text {st }}$ century skills: A review of recent research. Computers in Human Behavior, 63, 50-68. (http://dx.doi.org/10.1016/j.chb.2016.05.023)

Raphael, C., Bachen, C. \& Hernández-Ramos, P. (2012). Flow and cooperative learning in civic game play. New Media \& Society, 14(8), 1321-1338.

Rasoal, C., Eklund, J., \& Hansen, E. (2011). Toward a conceptualization of ethnocultural empathy. Journal of Social, Evolutionary, and Cultural Psychology, 5, 1-13.

Ratan, R.A. (2011). Self-presence in online gamers: Differences in gender and genre. Proceedings of the 13th Annual International Workshop on Presence. Edinburgh, Scotland. ISBN: 978-0-9792217-4-3

Schrader, C., \& Bastiaens, T. J. (2012). The influence of virtual presence: Effects on experienced cognitive load and learning outcomes in educational computer games. Computers in Human Behavior, 28(2), 648-658.

StataCorp LP. (2015). Stata/IC (13) [Computer program]. College Station, TX: Author.

Susana Ruiz. (2005). Darfur Is Dying. Browser.

Toussaint, L., \& Webb, J. R. (2005). Gender differences in the relationship between empathy and forgiveness. Journal of Social Psychology, 145(6), 673-685.

Van Looy, J., Courtois, C., De Vocht, M., \& De Marez, L. (2012). Player identification in online games: Validation of a scale for measuring identification in MMORPGs. Media Psychology, 15(2), 197-221.

Voiskounsky, A., \& Wang, S. (2014). Flow experience while computer gaming: Empirical study. Open Journal of Social Sciences, 2, 1-6. 
Wang, Y-W., Davidson, M. M., Yakushko O. F., et al. (2003). The scale of ethnocultural empathy: Development, validation, and reliability. Journal of Counseling Psychology, 50(2), 221-234.

Warren, S. J., Jones, G., Dolliver, B., \& Stein, R. A. (2012). Investigating games and simulations in educational research and theory: Enhancing academic communication and scholarship with a common language. International Journal of Gaming and Computer-Mediated Simulations, 4(4), 1-18.

Weibel, D., \& Wissmath, B. (2011). Immersion in computer games: The role of spatial presence and flow. International Journal of Computer Games Technology, Article ID 282345, 114.

Wouters, P., van Nimwegen, C., van Oostendorp, H., \& van der Spek, E. D. (2013). A metaanalysis of the cognitive and motivational effects of serious games. Journal of Educational Psychology, 105(2), 249-265.

Young, M. F., Slota, S., Cutter, A. B., Jalette, G., Mullin, G., Lai, B., Simeoni, Z., Tran, M., \& Yukhymenko, M. (2012). Our princess is in another castle: A review of trends in serious gaming for education. Review of Educational Research, 82(1), 61-89.

Yun Dai, D., \& Wind, A. P. (2011). Computer games and opportunity to learn (pp. 477-500). Implications for teaching students from low socioeconomic backgrounds. In S. Tobias \& J. D. Fletcher (Eds.) Computer games and instruction. Charlotte, NC: Information Age Publishing. 